\title{
Opportunity cost of ad hoc marine reserve design decisions: an example from South Australia
}

\author{
R. R. Stewart ${ }^{1, *}$, T. Noyce ${ }^{2}$, H. P. Possingham ${ }^{1}$ \\ ${ }^{1}$ The Ecology Centre, Department of Zoology and Entomology, The University of Queensland, St Lucia, Queensland 4072, Australia \\ ${ }^{2}$ Environment and Geographic Information Division, Department for Environment and Heritage, PO Box 550, Marleston, \\ South Australia 5033, Australia
}

\begin{abstract}
Like many states and territories, South Australia has a legacy of marine reserves considered to be inadequate to meet current conservation objectives. In this paper we configured exploratory marine reserve systems, using the software MARXAN, to examine how efficiently South Australia's existing marine reserves contribute to quantitative biodiversity conservation targets. Our aim was to compare marine reserve systems that retain South Australia's existing marine reserves with reserve systems that are free to either ignore or incorporate them. We devised a new interpretation of irreplaceability to identify planning units selected more than could be expected from chance alone. This is measured by comparing the observed selection frequency for an individual planning unit with a predicted selection frequency distribution. Knowing which sites make a valuable contribution to efficient marine reserve system design allows us to determine how well South Australia's existing reserves contribute to reservation goals when representation targets are set at 5, 10, 15, 20, 30 and $50 \%$ of conservation features. Existing marine reserves that fail to contribute to efficient marine reserve systems constitute 'opportunity costs'. We found that despite spanning less than $4 \%$ of South Australian state waters, locking in the existing ad hoc marine reserves presented considerable opportunity costs. Even with representation targets set at $50 \%$, more than half of South Australia's existing marine reserves were selected randomly or less in efficient marine reserve systems. Hence, ad hoc marine reserve systems are likely to be inefficient and may compromise effective conservation of marine biodiversity.
\end{abstract}

KEY WORDS: Marine reserves $\cdot$ Reserve selection $\cdot$ Efficiency $\cdot$ Decision theory $\cdot$ Representation targets $\cdot$ Irreplaceability $\cdot$ Biodiversity conservation $\cdot$ South Australia

\section{INTRODUCTION}

Marine protected areas are riding the wave of ocean governance reform (Kelleher 1997, Allison et al. 1998, Lauck et al. 1998, Boersma \& Parrish 1999, Carleton Ray 1999, Costanza et al. 1999, Agardi 2000, Roberts et al. 2003). In an environment that has traditionally been regarded as open-access commons, resource allocation via formalised and integrated management arrangements is emerging as a key component for the ecologically sustainable use of marine resources. Where such reform processes are grounded in space, whether it be in delineating areas suitable for aquaculture or areas of high conservation value, a decision theory framework and mathematical algorithms can provide repeatable, systematic and efficient solutions to spatial allocation problems (Possingham et al. 2001).

The application of mathematical algorithms to conservation planning and reserve system design is well known in terrestrial systems (Cocks \& Baird 1989, Pressey \& Nicholls 1989, Pressey et al. 1995, Margules \& Pressey 2000, Possingham et al. 2000). These methods provide decision support for efficient reserve system design through their capacity to include ecological, spatial and socio-economic information and their flexibility to respond quickly to a variety of treatments and scenarios set by planners, stakeholders and 
the community (Margules \& Nicholls 1988, Pressey \& Nicholls 1989, Vane-Wright et al. 1991, Nicholls \& Margules 1993, Williams et al. 1996, Rodrigues et al. 1999, Pressey \& Cowling 2001, McDonnell et al. 2002). Reserve selection algorithms hold significant potential as tools for systematic marine reserve design and are especially suited for the design of reserve systems (rather than constructing single reserves), where the information required on any one site needs to incorporate spatially explicit data and concepts such as adjacent land and sea uses, boundary lengths, connectivity and minimum reserve size. Yet it is only recently that reserve selection algorithms have been applied to marine reserve planning (Vanderklift et al. 1998, Ward et al. 1999, Ardron et al. 2001, Beck \& Odaya 2001, Leslie et al. 2003).

In this paper, we extend on the work of Ward et al. (1999) and Leslie et al. (2003) to apply mathematical methods for the design of marine reserve systems with different representation targets. In doing so, we examine how well an existing marine reserve system achieves conservation goals. For our case study, we considered the state waters of South Australia, located on the southern temperate coast of Australia and featuring some of the highest levels of marine biodiversity and endemism in Australia and the world (Edyvane 1999a). Creswell \& Thomas (1997) identified 15 marine protected areas (reserves) in South Australia amounting to almost 60000 ha. This figure represents $0.9 \%$ of South Australian state waters and $<0.2 \%$ of Australia's national total. More recently, the establishment of the Great Australian Bight Marine Park has increased the percentage of state waters protected in marine reserves to $3.1 \%$ (Edyvane 1999a).

Where marine reserve selection has occurred in South Australia, it has largely been ad hoc, rather than the outcome of a state-wide strategy to represent marine biodiversity, and is thought to be inadequate to meet current conservation objectives (Government of South Australia 1998, ANZECC 1999). Recognizing the shortfall of the existing marine reserve system, the South Australian government recently announced its intention to establish a system of marine reserves around the state (Government of South Australia 2001). We propose 2 planning scenarios for the design and selection of marine reserves in South Australia. The first scenario is free to either ignore or incorporate the existing marine reserves, whilst the second scenario must retain South Australia's existing marine reserve system.

As good reserve design should be based on established principles of conservation planning, we begin with a summary of key reserve planning principles. We then formulate the problem of reserve system design in mathematical terms and briefly introduce MARXAN
(Ball \& Possingham $2000^{1}$ ), an optimisation algorithm for marine reserve system selection. Our aim was to compare the performance of alternative marine reserve systems for the 2 planning scenarios when representation targets were set at 5,10,15,20,30 and $50 \%$ of conservation features. Because MARXAN can be set to ensure that all conservation targets will be met, we consider a range of measures that describe the performance of alternative reserve system solutions in terms that reflect secondary goals that the design process is attempting to capture. Pressey \& Nicholls (1989) described efficiency as one such measure. It recognises that the area available for reservation is often limited and so highly efficient marine reserve systems are more desirable. We evaluated the best marine reserve systems identified using measures of efficiency (Pressey \& Nicholls 1989), compactness (Possingham et al. 2000) and counts of the number of spatially separated reserves.

Extending on the work of Pressey et al. (1994), Ferrier et al. (2000) and Ball \& Possingham (2001), we devised a way of interpreting summed irreplaceability to assess the relative contribution of an individual site to reserve system goals. This approach uses selection frequency counts to determine whether sites were included in the reserve system more or less than by chance alone. We introduce the notion of 'opportunity cost' to quantify the inefficiencies of the existing system, defined as that portion of the existing marine reserves that would be selected by random or less, in the design of an efficient marine reserve system.

\section{Reserve planning principles}

We present some general reserve design principles derived from existing scientific theory and expert opinion. These principles serve to inform the reserve selection process by providing a clear statement about what reserve systems aim to achieve. They aim to circumvent the practice of creating ineffective and inefficient marine reserves that ultimately displaces the designation of more representative areas as competition for space becomes more intense (Pressey \& Nicholls 1989, Pressey et al. 1993, Pressey \& Tully 1994, Ballantine 1997, Hockey \& Branch 1997, Roberts et al. 2003).

Complementarity. Sites complement each other well if the species or habitats they contain are quite different, so their selection provides a combination of sites that together achieve the ultimate goal of comprehensiveness in the most efficient way. Consequently, plan-

\footnotetext{
${ }^{1}$ Ball IR, Possingham HP (2000) MARXAN v1.2: marine reserve design using spatially explicit annealing. www.ecology.uq.edu.au/marxan.htm
} 
ning for marine reserve systems should be informed by what is already contained within the existing reserves (Kirkpatrick 1983, Vane-Wright et al. 1991, Pressey et al. 1993). This means that the conservation value of an area is dynamic and will change as the reserve system is established (Margules \& Pressey 2000).

Comprehensiveness and representativeness. The notion of comprehensiveness implies sampling the full range of biodiversity within the marine reserve system. It should take into consideration biodiversity composition (species and genetic diversity), structure (physical organisation, e.g. habitat, patches) and function (ecological and evolutionary processes, e.g. reproduction, recruitment), providing for shifts in habitat preferences of marine species at different life stages (Noss 1990). Sampling should target both typical and atypical examples of the biodiversity features they are intended to represent.

Adequacy and self-sustainability. Persistence and long-term viability rely upon the degree of connectivity between reserves which, to borrow from the concepts of metapopulation dynamics, is a function of patch size, patch quality, recruitment, mortality and dispersal (e.g. local oceanography) (Crowder et al. 2000). Typically, systems of marine reserves should be configured so that sites interact in a positive fashion. Reserves located at source populations will ideally retain sufficient recruits to sustain local populations, with surplus larvae exported to other areas. Reserves located at sink populations are likely to depend upon replenishment from elsewhere, thereby diminishing prospects for long-term viability (Pulliam \& Danielson 1991, Roberts 1998).

Systems, replication and spatial cohesion. Because different ecological processes operate across several scales, marine populations are best supported by welldesigned reserve systems in which the whole is more than the sum of its parts. A systems-based approach is considered superior to the creation of isolated individual reserves for it can provide meaningful spatial relationships amongst sites for the maintenance of ecosystem linkages and connectivity, as well as offsetting effects from localized catastrophes (Ballantine 1997, Allison et al. 2003, Roberts et al. 2003). Furthermore, it is generally desirable for reserves to be both compact and contiguous, with some level of replication (Pressey \& Nicholls 1989, Ballantine 1997, Possingham et al. 2000).

Flexibility. The principle of flexibility arises from the non-unique occurrences of many biodiversity features. This has important implications for selection procedures for it means that conservation goals can be met in different ways. The more systems that can be appraised, the more likely the planner will find one which not only satisfies the conservation objectives, but also contributes to secondary goals such as design and costs. Having a variety of possible configurations gives scope for sensible resolutions of resource use conflicts (Kelleher \& Kenchington 1992). Equally important is the implication that we lose flexibility when sites with unique features are lost.

\section{METHODS}

\section{The reserve system design problem}

Reserve selection algorithms differ from scoring methods in how they define the reserve selection problem. At the core of the problem is the goal of minimising the area of the reserve system whilst meeting conservation targets (Bedward et al. 1991, Pressey et al. 1993, 1997, Leslie et al. 2003). This was first described by Kirkpatrick (1983) as the minimum representation problem. It is derived from the idea that while biodiversity conservation objectives may wish to maximise the area within the reserve system, they must compete against social, economic and management constraints (Possingham et al. 2000). This is formulated by McDonnell et al. (2002) as a mathematical programming problem:

Minimise the objective function

$$
\sum_{i=1}^{M} c_{i} x_{i}+\operatorname{BLM}\left(\sum_{i=1}^{M} x_{i} l_{i}-0.5 \sum_{i=1}^{M} x_{i} \sum_{k=1}^{M} x_{k} b_{i k}\right)
$$

subject to the constraints:

$$
\begin{aligned}
& \sum_{i=1}^{M} a_{i j} x_{i}>t_{j} \sum_{i=1}^{M} a_{i j} \text { for all } j=1 \ldots N, \\
& x_{i} \in\{0,1\} \quad \text { for all } i=1 \ldots M,
\end{aligned}
$$

where $x_{i}$ is the control variable such that if $x_{i}=1$ then site $i$ is selected in the reserve system, and if $x_{i}=0$ then site $i$ is not in the reserve system. The parameter $C_{i}$ is the 'cost' of site $i, l_{i}$ is the perimeter or boundary length of site $i, b_{i k}$ is the common boundary length of sites $i$ and $k$, and BLM is a boundary length modifier that converts the reserve system cost and its boundary length into a common currency. The parameter $N$ is the number of conservation features and $M$ is the number of sites.

Eq. (1) is the objective function which seeks to minimise a linear combination of site costs and reserve system boundary length. Eq. (2) is the set of constraints that ensure the target for each conservation feature is met, where $a_{i j}$ is the abundance of feature type $j$ in site $i$ and $t_{j}$ sets the target fraction for each feature type. The target fraction can be modified to suit different scenarios (for example we may wish to have higher representation of certain habitat types). Our objective is to identify a number of reasonably good marine 
reserve systems that come close to minimising the objective function. A feasible solution is one that contains a set of sites (depicted by the control variable $x_{i}$ ) such that all the constraints are met.

The reserve system design algorithm, MARXAN. Because our reserve design problem is large (with $2^{3119}$ possible solutions), it is impossible to find an optimal solution in reasonable time. We used the reserve design software MARXAN, created by Ball \& Possingham $\left(2000^{1}\right)$ for systematic marine reserve design. MARXAN uses a variety of optimisation methods to produce solutions to the reserve system design problem. We used the simulated annealing feature which consistently out-performs simpler iterative or heuristic algorithms, such as the greedy and rarity-based selection algorithms, particularly for complex spatial problems (Pressey \& Nicholls 1989, Pressey et al. 1997, Ball 2000, McDonnell et al. 2002). The method is fast, allowing one to find a number of good solutions to the problem. Each solution is scored against the objective function (Eq. 1) according to how well it meets the prescribed targets and design constraints.

Spatial design requirements can be incorporated into the method in several ways. We use the boundary length modifier (BLM), which determines the relative importance placed on minimising the boundary length relative to minimising cost. Leslie et al. (2003) found this was an effective way to exert control over the spatial arrangement of a marine reserve network, as increasing the BLM gives preference to the inclusion of sites which minimise the overall perimeter, thereby clustering the sites and generating a well connected reserve system.

Planning units. The study area was defined by the 3 nautical mile legal limits to South Australian state waters. This area was divided into 3119 planning units (sites), with each planning unit forming a $5 \times 5 \mathrm{~km}$ cell. Due to the study area's irregular shape, a number of planning units were truncated at the coastline and offshore islands, providing some variation in planning unit size (area) and boundary length. Information on the amount of conservation features contained within each planning unit was compiled.

Conservation features and feature targets. Regardless of the reserve selection methodology, fulfilment of biodiversity conservation objectives through in situ conservation is largely premised on the representation of biodiversity surrogates at appropriate levels; yet the information available for marine planning is limited, with data coverage often biased towards special interest sites (such as existing marine reserves) or charismatic species. We selected datasets that provided consistent quality and coverage across the state waters of South Australia. Data was sourced from state government agencies, with the chosen conservation features

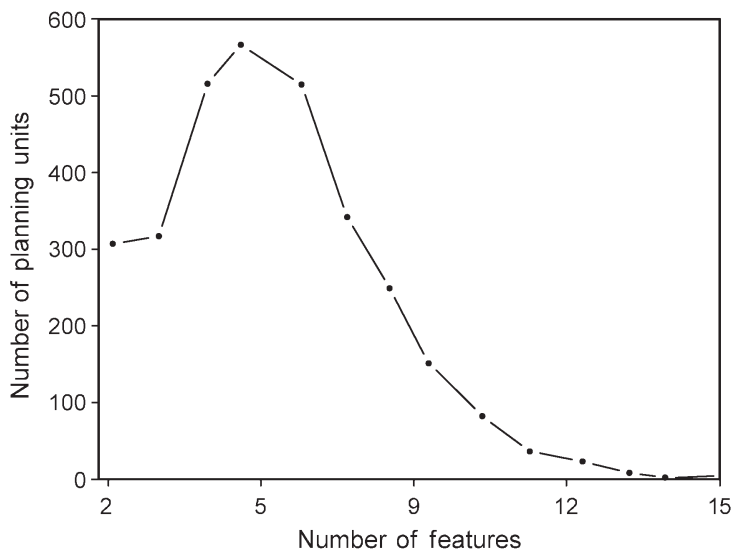

Fig. 1. Distribution of conservation features for the South Australian dataset. No. of conservation features per planning unit. A full description of features is provided in Appendix 1

derived from 6 biophysical data layers (Appendix 1). The amount of each conservation feature $j$, in each planning unit $i$, formed the basic data matrix $a_{i j}$. This equated to 102 conservation features distributed across 3119 sites, producing approximately 17000 records. The distribution of conservation features across the planning units is shown in Fig. 1. For this study, representation targets $t$, were set at values between 5,10 , $15,20,30$ and $50 \%$ of the total amount of each conservation feature type.

\section{Marine reserve planning scenarios}

We formulated the reserve design problem for 2 alternative planning scenarios: the 'No Reserves' scenario and the 'Reserves Fixed' scenario.

The No Reserves scenario follows the problem defined by Eqs. (1) \& (2). Ignoring the status of South Australia's existing marine reserves, our control variable $x_{i}$ can assume a value of either 0 or 1 for all 3119 planning units. If $x_{i}=1$, then that planning unit forms part of the reserve system, and if $x_{i}=0$, then planning unit $i$ is excluded from the reserve system. We set the cost variable $c_{i}$ to 1 , which means that every planning unit has equal cost. The parameter $l_{i}$ is the boundary length in kilometres of planning unit $i$, and $b_{i k}$ is the common boundary length in kilometres of planning units $i$ and $k$. This serves to minimise the cost of planning units that share a common boundary. The boundary length modifier (BLM) was fixed at 0.5 to minimise fragmentation and to produce both reasonably compact and efficient reserve systems (Stewart \& Possingham in press). Lastly, the abundance of the conservation feature type $j$ in planning unit $i$ is depicted by the variable $a_{i j}$.

The Reserves Fixed scenario generates marine reserve systems using South Australia's existing marine reserves 
as the seed for all solutions. Constructing the best reserve system we can with the existing system locked in and comparing this with the best reserve systems of the No Reserves scenario allows us to evaluate the performance of South Australia's existing marine reserves. We adopt the matrix defined for the No Reserves scenario with minor amendment, since fewer planning units are now available for selection due to the existing reserves being locked in. We revisit Eqs. (1) \& (2) to formulate the problem as before but with $x_{i}=1$ for all planning units contained within an existing marine reserve. The control variable $x_{i}$ now assumes a value of either 0 or 1 for only 2831 planning units. The marine reserve system design problem is to make additions to the 288 sites that contain South Australia's existing marine reserves until conservation targets are met.

Evaluating reserve system performance. Marine reserve systems were generated to evaluate the effect of 2 variable factors: the planning scenario (No Reserves and Reserves Fixed) and the representation target (set at 5, $10,15,20,30$, and $50 \%$ ). This presents 12 different planning problems, with 1000 independent runs of the algorithm performed for each. With many alternative reserve systems generated, our task was to identify the combination of planning units that made up the 'best' marine reserve system. As we also wished to consider the contribution of individual planning units to the reserve system goals, we were interested in the number of times a planning unit was chosen out of the total number of runs, otherwise referred to as 'summed irreplaceability' (Ball \& Possingham 2001, Leslie et al. 2003).

Performance measures for the best marine reserve systems: We examined the performance of marine reserve systems using the summary data generated by MARXAN. Summary data included measures of the objective function score, the number of planning units in the marine reserve system and the overall boundary length. The best marine reserve system was identified as the solution with the lowest objective function score, then mapped in a geographical information system (GIS) to calculate the total area, boundary length (perimeter) and number of individual reserves in the reserve system. Individual reserves were identified as a cluster of adjacent planning units that share a common boundary. This process was repeated for the best marine reserve system generated for each planning problem.

Because the solution with the lowest objective function may not always be the most desirable (or practical) solution, we sought additional measures to evaluate alternative marine reserve system configurations and quantify trade-offs that may arise when different constraints are considered. We used Pressey's measure of efficiency (Pressey \& Nicholls 1989) to describe how efficiently representation targets are met. It varies from 0 to 1 , with 1 being the most efficient solution.

$$
E=1-X / T
$$

where $E$ is efficiency, $X$ is the number of planning units needed to meet the constraints, and $T$ is the total number of planning units. As we were also interested in the spatial configuration of the reserve system, we used compactness to assess the degree of spatial clustering in the reserve systems. This is defined in Eq. (4) as the ratio between the perimeter of the marine reserve system and the circumference of a circle of the same area (the theoretical minimum) (Possingham et al. 2000):

$$
\text { Ratio }=\frac{\text { Boundary length }}{2 \sqrt{\pi \times \text { Area }}}
$$

Values approaching 1 resemble the shape of a circle and are highly clustered. In calculating both compactness and efficiency, we used a measure for boundary length derived through GIS processing.

Summed irreplaceability: Irreplaceability was first described by Pressey et al. $(1993,1994)$ as the likelihood of a site being required as part of a representative conservation system (Ferrier et al. 2000). It provides a measure of the contribution of individual planning units to the marine reserve system goals by indicating how frequently a site is amongst solutions that meet all biodiversity targets. Summed irreplaceability is slightly different from irreplaceability and is reported as the frequency of all the reserve systems to which a planning unit belongs out of the total number of systems generated (Ball \& Possingham 2001). Because the selection of planning units incorporates a spatial configuration component, Ball \& Possingham (2001) explain how a planning unit might appear frequently, partly because of what it contains but also because of its spatial relationship with other sites. Here, we used selection frequency probability distributions to devise a new technique that allows one to assign meaningful measures of summed irreplaceability to individual planning units. This enabled us to compare planning units that perform no better than random (or, as Pressey \& Tulley [1994] described, are ad hoc) with those that are selected more often than could be expected from chance alone.

We compared selection frequencies for planning units in a given planning problem with selection frequencies for a randomly sampled population of given combination size. The combination size was taken as the average number of planning units contained in a marine reserve system for a given planning problem, calculated from 1000 repeat runs. The probability that a planning unit could be expected to be selected by chance alone was defined according to the formula:

$$
P=(C-R) /(T-R)
$$


where $C$ is the combination size and $R$ is the number of planning units not available for selection, which under the Reserves Fixed scenario was the number of planning units that make up South Australia's existing marine reserves. The parameter $T$ is the total number of planning units $(n=3119)$. Predicted selection frequency distributions were then derived and Tukey's $95 \%$ confidence interval determined. By comparing the selection frequencies observed for the planning scenarios with the predicted selection frequencies derived from our parameters, we could assert that a planning unit selected more often than the upper $95 \%$ confidence limit of the predicted selection frequency was included in the reserve system more than could be expected from chance alone and could thus be considered to be irreplaceable.

Opportunity costs: We applied this new interpretation of summed irreplaceability to evaluate the contribution of South Australia's existing marine reserves to reservation goals and objectives. Knowing which planning units are irreplaceable means we can also identify planning units that are 'replaceable' (i.e. selected no more than could be expected by chance alone). Our aim was to determine the inefficiencies (opportunity cost) of South Australia's existing marine reserves by identifying the portion of replaceable planning unit's that make up South Australia's existing marine reserves.

Because the existing marine reserves are locked in to every marine system in the Reserves Fixed scenario, these planning units are reported as $100 \%$ irreplaceable. However, this result is purely a construct of the constraints of the reserve design problem and doesn't tell us much about the planning unit's contribution to an efficient and representative marine reserve system. One way of examining the contribution of fixed planning units to the reservation goals is to generate multiple solutions, as though the existing reserve system doesn't exist. These are the conditions of the No Reserves scenario. Our analysis examined the subset of planning units representing South Australia's marine reserves and recorded the number of times units appeared in marine reserve systems generated under the No Reserves scenario. Planning units selected less than or equal to what would be expected from random sampling were identified using the rule:

If $X_{r} \leq X_{0.975}$, then planning unit $r$ is replaceable where $X_{r} \in\{0 \ldots 1000\}$ for all existing reserves $r=1 \ldots 288$

where $X_{r}$ is the observed selection frequency for planning unit $r$ in the No Reserves scenario and $r$ is the subset of planning units locked in under the Reserves Fixed scenario. $F(x)=0.975$ where $x$ is the predicted selection frequency at the upper $95 \%$ confidence limit. The opportunity cost can be reported for the existing reserve system in its entirety, or at the level of individ- ual reserves. In either case, it is the area of the subset of planning units found to be replaceable divided by the total area of the existing reserves. Areas were calculated using the area of the existing marine reserves dataset, where this varied from the area encompassed by the planning units.

\section{RESULTS AND DISCUSSION}

\section{Alternative marine reserve system solutions for South Australia}

Examples of the best marine reserve systems for different planning problems are shown in Fig. 2. Here, we illustrate the requirement for much larger reserve systems as representation targets are increased from $5 \%$ (Fig. 2A) to $50 \%$ (Fig. 2B). Included also are the alternative marine reserve systems for the No Reserves and Reserves Fixed scenarios. The effect of the planning scenario on marine reserve system solutions at equivalent representation targets is not obvious from Fig. 2, so marine reserve systems generated from these and other planning problems are described using performance measures reported in Table 1.

Although all marine reserve systems identified were successful in achieving their goal, how well they did was largely a function of the constraints of the reserve design problem. The most efficient marine reserve system identified was generated in the No Reserves scenario at $5 \%$ representation targets (Table 1 ). The efficiency of marine reserve systems then decreased as targets increased. This is due to efficiency being a direct measure of efficiency of sampling (Pressey \& Nicholls 1989), so marine reserve systems requiring fewer planning units will always be more efficient. Notwithstanding, we found measures of efficiency to be useful for comparisons of the No Reserves and Reserves Fixed reserve systems at the equivalent representation targets, with the Reserves Fixed scenario producing less efficient marine reserve systems in every case. The inefficiency of Reserves Fixed systems is best illustrated at $5 \%$ representation targets with 402 planning units (288 of which make up South Australia's existing marine reserve system) required to achieve the same targets that the No Reserves scenario met with just 169 planning units.

Intuitively, we would expect the performance of the Reserves Fixed marine reserve systems to improve as representation targets increase. Although this was observed to some degree, the No Reserves systems were always more efficient than the Reserves Fixed scenario at an equivalent representation target. Single-factor analysis of variance confirmed that the reserve system combination size (the average number of planning 

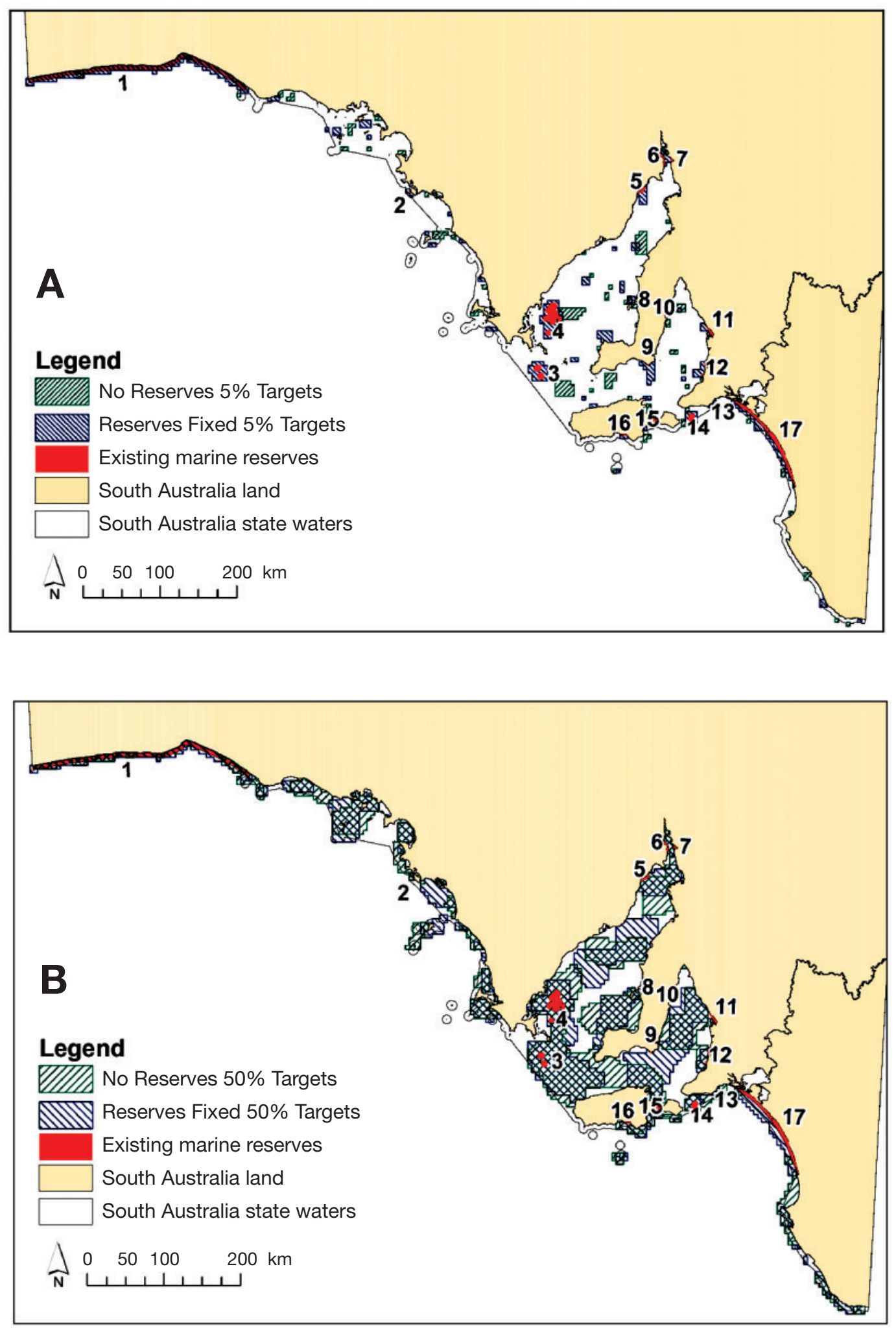

Fig. 2. Alternative marine reserve systems for the No Reserves and Reserves Fixed scenarios with representation targets set (A) at $5 \%$ and (B) at $50 \%$. The locations of South Australia's existing marine reserves are shown in red (individual marine reserves are identified in Appendix 1). These areas are locked in to every marine reserve system generated in the Reserves Fixed scenario. Under the No Reserves scenario, the existing reserves can be either ignored or incorporated. For summary data see Table 1 
Table 1. Summary data for the best marine reserve systems generated for 2 planning scenarios at different representation targets. Marine reserve systems identified under the No Reserves scenario were always more efficient than systems identified under the Reserves Fixed scenario at an equivalent representation target. For measures of compactness, a value of 1 is the ideal (most compact) configuration. Measures of efficiency are bound between 0 and 1, with 1 being the most efficient system. The combination size is the no. of planning units in a reserve system (calculated from 1000 runs of the algorithm); SD = standard deviation

\begin{tabular}{|c|c|c|c|c|c|c|c|c|c|}
\hline Scenario & $\begin{array}{c}\text { Target } \\
(\%)\end{array}$ & Score & $\begin{array}{c}\text { No. of planning } \\
\text { units }\end{array}$ & $\begin{array}{l}\text { No. of } \\
\text { reserves }\end{array}$ & $\begin{array}{l}\text { Perimeter } \\
\quad(\mathrm{km})\end{array}$ & $\begin{array}{l}\text { Area } \\
\left(\mathrm{km}^{2}\right)\end{array}$ & Compactness & Efficiency & $\begin{array}{l}\text { Combination } \\
\text { size } \pm \mathrm{SD}\end{array}$ \\
\hline \multirow[t]{6}{*}{ No Reserves } & 5 & 996 & 169 & 58 & 1695 & 3743 & 7.81 & 0.95 & $168 \pm 3.87$ \\
\hline & 10 & 1419 & 315 & 49 & 2233 & 7394 & 7.33 & 0.90 & $314 \pm 5.17$ \\
\hline & 15 & 1811 & 461 & 44 & 2723 & 10936 & 7.35 & 0.85 & $457 \pm 6.60$ \\
\hline & 20 & 2178 & 598 & 44 & 3165 & 14264 & 7.48 & 0.81 & $602 \pm 7.51$ \\
\hline & 30 & 2866 & 896 & 45 & 3931 & 21234 & 7.61 & 0.71 & $890 \pm 8.76$ \\
\hline & 50 & 4152 & 1472 & 35 & 5240 & 35135 & 7.89 & 0.53 & $1476 \pm 12.51$ \\
\hline \multirow[t]{6}{*}{ Reserves Fixed } & 5 & 2107 & 402 & 46 & 3308 & 8020 & 10.42 & 0.87 & $404 \pm 4.43$ \\
\hline & 10 & 2496 & 531 & 47 & 3820 & 11311 & 10.13 & 0.83 & $527 \pm 6.01$ \\
\hline & 15 & 2795 & 652 & 43 & 4147 & 14233 & 9.81 & 0.79 & $651 \pm 7.11$ \\
\hline & 20 & 3086 & 771 & 45 & 5504 & 17061 & 7.93 & 0.75 & $774 \pm 8.17$ \\
\hline & 30 & 3596 & 1020 & 37 & 4996 & 23064 & 9.28 & 0.67 & $1031 \pm 8.83$ \\
\hline & 50 & 4753 & 1581 & 38 & 6127 & 36427 & 9.06 & 0.49 & $1580 \pm 13.15$ \\
\hline
\end{tabular}

units in 1000 marine reserve systems) was significantly different $(\mathrm{p}<0.05)$ between the 2 scenarios at the equivalent representation target. From these results, we conclude that certain features must be contained within the existing marine reserve system at levels exceeding the required target, even when targets are as high as $50 \%$. As representation of features surplus to the prescribed target goes unrewarded, this translates into larger and less efficient marine reserve systems.

A second way of evaluating the performance of marine reserve systems is to measure their compactness (Table 1). The No Reserves systems were always more compact than the Reserves Fixed systems, irrespective of the target. Even when the Reserves Fixed systems comprised fewer individual reserves than the No Reserves scenario, as reported at 5, 10, 15 and 30\% targets, their configuration was more fragmented. This result is perhaps counter-intuitive, as one would normally presume that fewer reserves would deliver a more compact solution. However, there are 2 parts to a reserve system's compactness, the number of reserves and the shape. The less compact Reserves Fixed systems most likely resulted from the inclusion of existing reserves such as the Coorong and the Great Australian Bight Marine Park (GABMP) which are characterised by a high perimeter-area ratio.

Next, we examined the selection frequencies for individual planning units to assess their importance for efficient marine reserve system design. We applied our new interpretation of irreplaceability to identify planning units selected more than could be expected from chance alone, with the top 100 irreplaceable planning units identified from these. The example in Fig. 3 illustrates the distribution of irreplaceable areas for both scenarios when representation targets were set at
$20 \%$. We considered the top 100 irreplaceable planning units to be key locations for conservation planning, with several locations common to both planning scenarios. With only 1 planning unit in the Reserves Fixed scenario identified as $100 \%$ irreplaceable, this suggests that the distribution of our chosen biodiversity features in South Australia affords some degree of flexibility for marine reserve system design.

\section{Opportunity costs of ad hoc marine reserve design}

Knowing that the inefficiencies of marine reserve systems identified under the Reserves Fixed marine reserve systems were due to the inclusion of South Australia's existing marine reserves, we sought to determine the cause of these inefficiencies. Our analyses were performed on the subset of planning units corresponding to South Australia's existing marine reserves to determine the opportunity cost for the whole of the existing reserve system and then for each individual reserve at different representation targets. These results are presented in Fig. 4 with the opportunity cost calculated as the replaceable fraction of South Australia's existing reserves. At $5 \%$ targets this amounted to an opportunity cost of $64 \%$ that reduced to $51 \%$ when representation targets were increased to $50 \%$. Therefore, at best, more than half the area of South Australia's existing reserves resulted in an opportunity cost to efficient marine reserve selection, demonstrating the inefficiency of ad hoc marine reserve selection. Increasing the representation targets failed to greatly improve the performance of the existing marine reserve system.

Next, we examined whether any reserve in particular accounted for the inefficiencies of the existing 

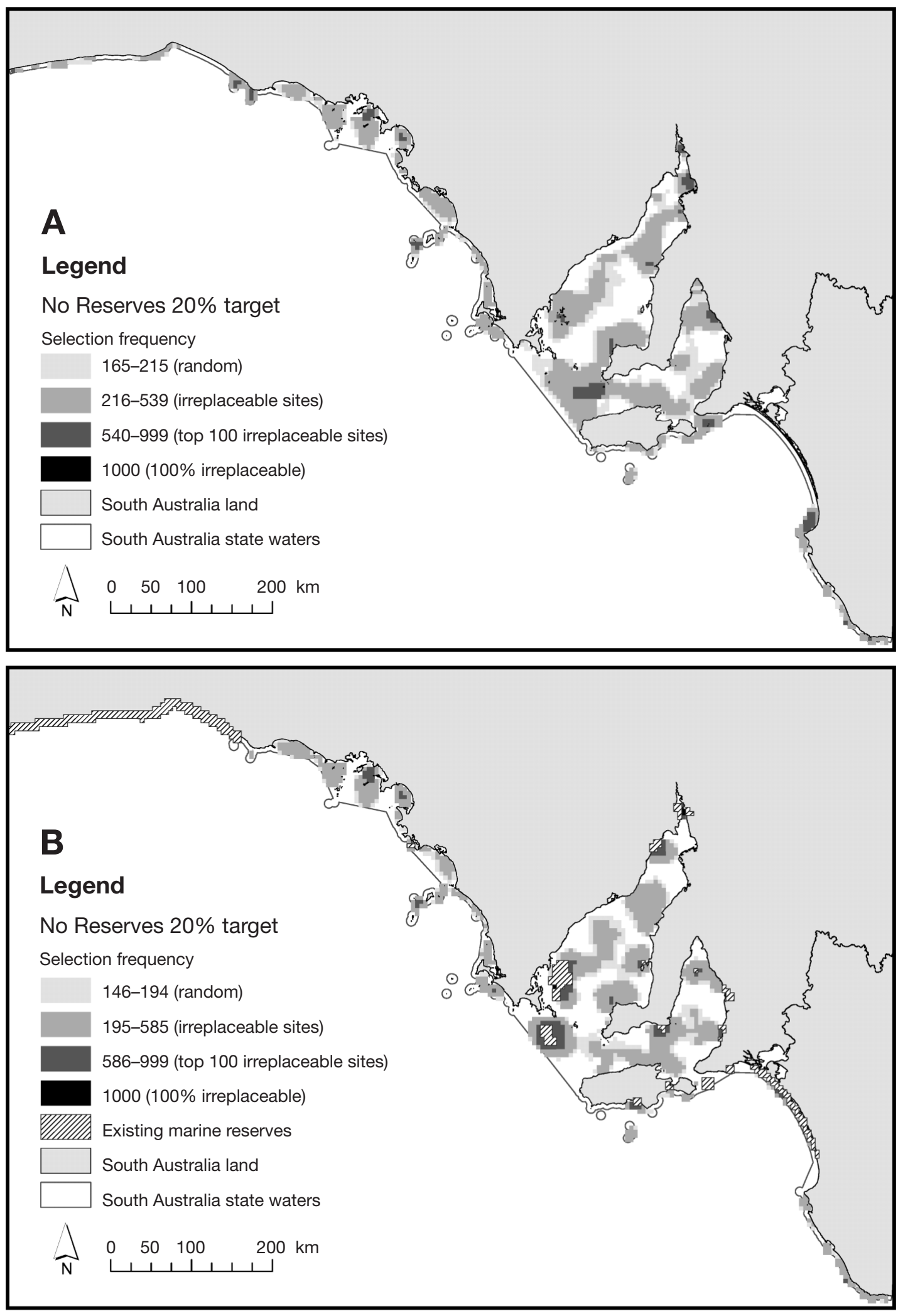

Fig. 3. Selection frequency counts are shown for planning units contained within efficient marine reserve systems under the (A) No Reserves and (B) Reserves Fixed scenarios when representation targets are set at $20 \%$. Irreplaceable planning units are defined as those contained within marine reserve systems more times than could be expected from chance alone. The top 100 irreplaceable planning units are regarded as core areas for conservation planning, some of which are common to both planning scenarios and may be considered key locations for efficient marine reserve design. Planning units selected as often as could be expected from random sampling alone are categorised as Random 


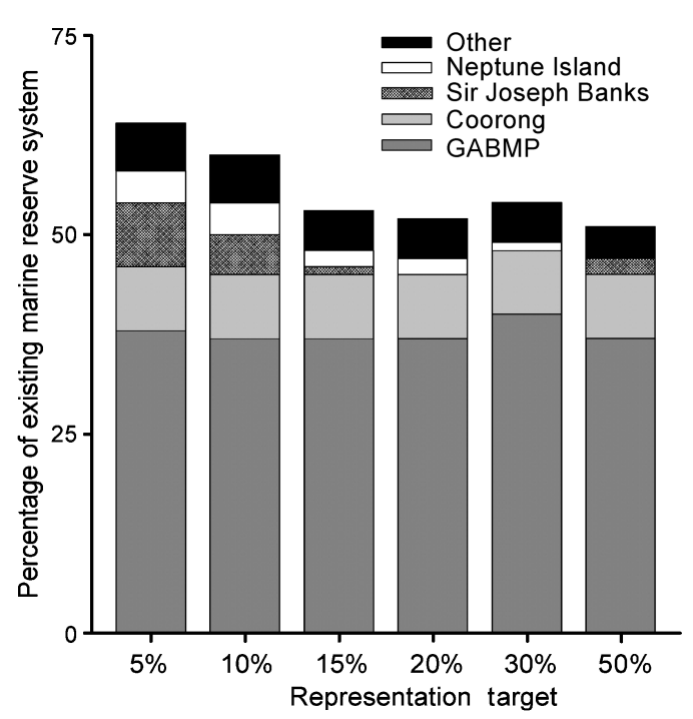

Fig. 4. The opportunity cost of South Australia's existing marine reserve system at different representation targets. Individual marine reserves representing the greatest opportunity cost to the existing system are highlighted and all exceed $100 \mathrm{~km}^{2}$ in size. Reserves defined as 'Other' (Point Labatt, Whyalla-Cowley, Blanche Harbour, Yatala Harbour, Zanoni, Barker Inlet/Chapman Creek, Port Noarlunga, Aldinga Reef, Troubridge Hill, Goose Island, American River, Seal Bay/Bales Beach, The Pages, West Island) represent the smallest opportunity cost to the existing system overall

marine reserve system (Fig. 4). Although the entire area of several existing marine reserves represented a $100 \%$ opportunity cost, i.e. no part of their area selected more than by chance at any representation target (Point Labatt, Troubridge Hill and American River), their combined size amounted to $<1 \%$ of the existing marine reserve system. Therefore, their individual performance did not correspond to a high opportunity cost to the existing marine reserve system as a whole. By comparison, the Great Australian Bight Marine Park (GABMP) makes up almost $60 \%$ of South Australia's existing marine reserve system, so the opportunity cost of the system was particularly sensitive to the performance of this individual reserve. Indeed, the individual reserves identified in Fig. 4 are the only marine reserves in South Australia to exceed $100 \mathrm{~km}^{2}$. The relatively greater size of these reserves ensures that their performance was more likely to impact on the performance of the system. Even for reserves that we considered to make an efficient contribution to reservation goals due to more than $50 \%$ of their area being irreplaceable (Sir Joseph Banks Group), their relatively larger size means that any portion of replaceable areas was more likely to result in a higher opportunity cost to the system.

Of the larger reserves, the GABMP was especially costly. It contributed to the reservation goals most efficiently at 15, 20 and $50 \%$ targets, resulting in an opportunity cost of $61 \%$ of the reserve itself and $37 \%$ of South Australia's existing marine reserve system. This is equivalent to $>950 \mathrm{~km}^{2}$ from the GABMP alone that was never selected more than by chance in efficient marine reserve systems. The distribution of replaceable planning units for the GABMP was mapped (Fig. 5) at representation targets of 5, 20 and 50\%. A high degree of nestedness occurred for replaceable areas as targets were varied, such that planning units that were replaceable with $50 \%$ representation targets tended to remain replaceable at lower targets. This approach can similarly be applied to identify those parts of existing marine reserves that make an efficient contribution to biodiversity conservation objectives.

\section{Conclusions}

We have shown how a properly posed marine reserve system design problem and mathematical algorithms can be used to investigate the consequences of alternative representation targets and planning scenarios. We highlighted the need for systematic and efficient selection methods through our assessment of the contribution of South Australia's existing marine reserve system to meeting conservation targets.

Measures of efficiency (Pressey \& Nicholls 1989), compactness (Possingham et al. 2000), and the number of individual reserves were examples used here to describe the performance of alternative marine system solutions. We encountered limitations when using efficiency to compare between marine reserve systems at different representation targets, as it failed to account for the additional area required if higher targets are to be met. One way of standardising measures of efficiency may be to compare the reserve systems generated with marine reserve systems identified when there are no spatial constraints $(B L M=0)$. Reserve systems configured under these conditions place the greatest importance on minimising area, thus delivering marine reserve systems with the least number of planning units, and could be considered the nearminimum solution for a particular planning problem (Possingham et al. 2000, Stewart \& Possingham in press).

A new application of summed irreplaceability that identifies areas that make an efficient contribution to representative conservation goals was presented. This serves to address the practical problem of how and where reserve selection should proceed through the identification of irreplaceable or priority areas. Because reserve planning is iterative and the irreplaceability value of an individual site is dynamic, having the tools to explore the relative contribution of an individual site can support decision-making for sequential 


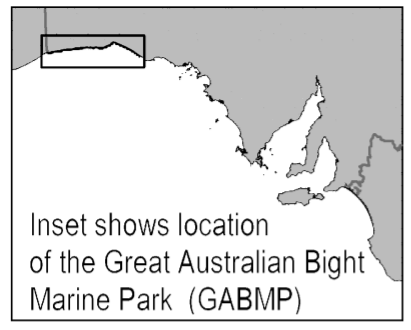

\section{Opportunity cost for the Great Australian Bight Marine Park (GABMP)}

Replaceable planning units

Irreplaceable planning units
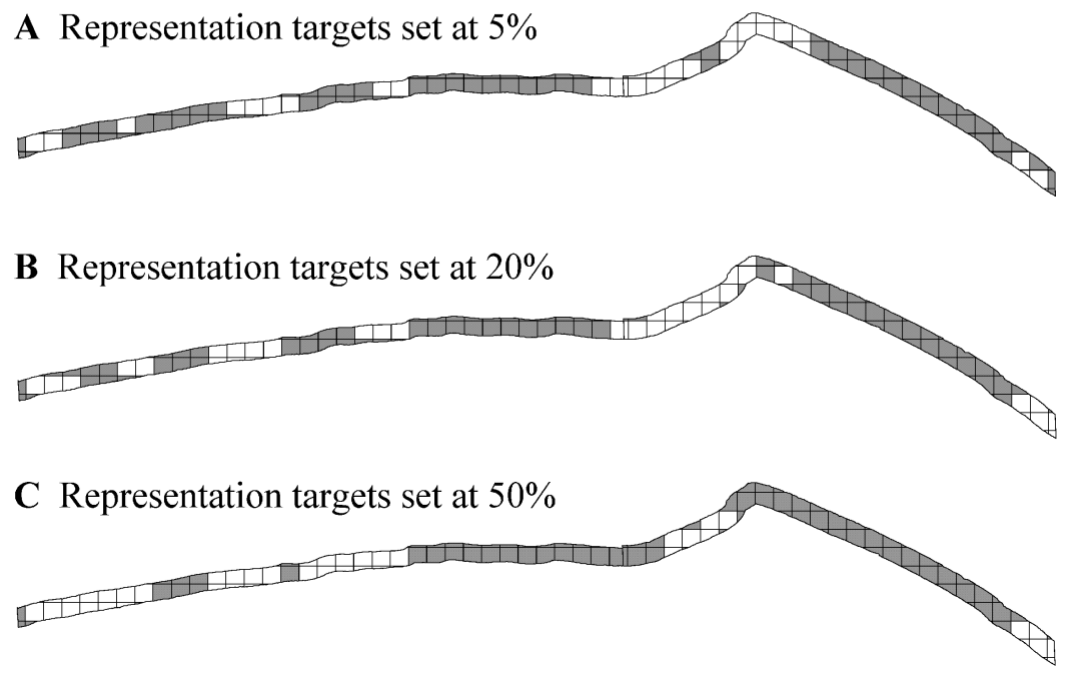

Fig. 5. Distribution of the replaceable and irreplaceable planning units across the GABMP reserve. Replaceable areas are identified as a measure of the opportunity cost, for their inclusion results in the identification of inefficient and less compact marine reserve systems. At representation targets of 5, 20 and $50 \%$ the opportunity cost of the GABMP was 64,61 and $62 \%$ of the total reserve area. Increasing representation targets did not improve the performance of the reserve, which is considered to make a poor contribution to efficient marine reserve design (more than half of its area reported as an opportunity cost)

when feature targets were as high as $50 \%$. We regard their poor performance to be an opportunity cost, for they may constrain effective conservation of marine biodiversity by compromising the ability to select more suitable sites. Furthermore, the inclusion of these areas in many cases may displace commercial effort to non-reserved areas, some of which may have irreplaceable value for conservation planning.

Whilst we don't expect reserve planners to abandon existing reserves on the basis of the results shown here, we do want to highlight that past decisions yield great impact on the design of marine reserve systems. We also recognise that part of the existing reserve system does make an efficient contribution to achieving biodiversity conservation targets. Although this contribution might be incidental, knowing which areas are key or irreplaceable to achieving conservation goals provides valuable information to support management decisions and to determine where effort should be targeted. With several of South Australia's marine reserves being merely extensions of terrestrial reserves and without formal management arrangements that explicitly incorporate marine biodiversity conservation objectives, a practical

reserve selection. In addition, it provides a means to evaluate the impact of decisions when sites are lost or changes to the reserve system are made. Similar optimisation methods to those used for marine reserve system selection could be used to guide decisions for siting of commercial and recreational activities, providing the flexibility to negotiate arrangements that achieve both conservation and socio-economic objectives.

A second application for irreplaceability relates to the principle of complementarity and examines the opportunity cost that arises when marine reserve systems are built around marine reserves selected in an ad hoc manner. Because conservation planning is informed by what is contained within the existing marine reserves, how well these areas contribute to the system targets and goals affects the performance of the system as a whole. Given the ad hoc manner in which South Australian marine reserves have been chosen in the past, it is not surprising to find that less than half of the existing reserve system made an efficient contribution even application of this work may be to utilise this information to review current management arrangements and ensure that areas are protected and managed appropriately.

When defining the problem of marine reserve system design it is important to recognise that there are 2 sources of uncertainty. The first (epistemic uncertainty) arises from incomplete knowledge or limitations of data and, in so far as it relates to marine biodiversity and reserve design, will be present in all selection methodologies. Although we present a practical case study, we have not concerned ourselves with this type of uncertainty, for our principal goal was to evaluate a methodology and suite of tools. Confidence in the accuracy of our findings would be improved by accounting for this kind of uncertainty through the inclusion of additional datasets, improving data quality by evaluating the potential effects of error propagation and consideration of ecological processes (Flather et al. 1997, Freitag et al. 1998). The second type of uncertainty is called vagueness and is attributed to the imprecise nature of lan- 
guage, which can lead to ambiguities and misunderstandings (Regan et al. 2000). We are encouraged by the capacity of mathematical methods to reduce vague- ness and subjectivity by relating to clearly articulated goals and proceeding in an efficient and systematic manner. Even more important perhaps is their capacity

Appendix 1. Conservation features were identified for state waters using 6 data layers obtained from South Australian state government agencies. An additional feature class was delineated to represent the status of South Australia's existing reserves

Biogeographic regions (meso-scale: 100 to $1000 \mathrm{~s} \mathrm{~km}$ )

Biogeographic regions have been identified at the national level using a marine ecosystem-based classification scheme, known as the Interim Marine and Coastal Regionalisation of Australia (IMCRA). The scheme was derived using a combination of expert ecological knowledge from the field and interpretation of existing regionalisations (IMCRA Technical Group 1997), which include sea floor topography, sea floor sediments, physical oceanographic water column, coastal zone geomorphology and pelagic and demersal fish regionalisations. There are 60 bioregions delineated for the Australian coastal and offshore waters and 8 of these occur wholly or partly within South Australian state waters.

\section{Biounits (micro-scale: 10 to $100 \mathrm{~s} \mathrm{~km}$ )}

At this micro-scale level, distinct regional and local variations in habitat and biodiversity are classified on the basis of local-scale ecological units (i.e. rocky shores, shoals or reef systems) and information on the spatial extent of these units. South Australia's micro-scale biounits were defined primarily on the basis of coastal physiography, topography and major marine physical habitat or seascape features, as well as habitat distribution (Edyvane 1999b). A total of 35 biounits have been identified and comprise 30 coastal biounits and 5 offshore units (Edyvane 1999b). Seaward boundaries of the coastal biounits were defined using the $30 \mathrm{~m}$ bathymetric contour. The offshore biounit boundaries were drawn at the $50 \mathrm{~m}$ depth contour.

\section{Marine benthic habitat maps}

Marine benthic habitat coverage has been mapped for coastal and gulf waters of the state. Habitats were identified by tracing discernible underwater features on satellite images and using aerial photographs for 'truthing'. The resulting dataset uses biological data for classification of seagrass densities and geomorphological descriptions for reefs. As a benthic classification scheme has not yet been developed for South Australia, habitat type is classified at a broad level (i.e. seagrass, platform reef, sand) and does not incorporate information on the dominant species assemblages. We identified 6 unique conservation features in this feature class.

\section{Coastal saltmarsh and mangrove habitats}

Intertidal vegetation of the coastal regions of South Australia has been identified from digitised 1:40000, 1:15000 and 1:10000 non-rectified aerial photography. Habitats were classified and coded using landform, life form and condition categories. Classification was based on aerial photo interpretation, survey data, ground truthing and expert knowledge. In total, 65 habitat classes were identified with
11 of these relating to intertidal or tidal areas. These classes were collapsed into the more generalised categories of intertidal/tidal marine algae; intertidal and tidal bare sand; intertidal/tidal seagrass, mangroves and saltmarsh. This classification provided a further 5 unique conservation features.

\section{Species occurrence}

Species occurrence data were incorporated where coverage extended across the study area and occurrence records were of sufficient quality. On these grounds, we identified 3 conservation features from the data layers available for South Australian distributions of seabirds, Australian sea lions and New Zealand fur seals.

The seabirds of South Australia dataset describes population and breeding seasons, including mainland and offshore island sites. The dataset is suitable for the identification of significant seabird habitat communities within South Australia. Australian sea lion (Neophoca cinerea) and New Zealand fur seal (Artocephalus forsteri) locations within South Australian waters are identified, with population, breeding season and breeding and haul out sites for both the mainland and island locations.

\section{Bathymetry}

This dataset is a compilation of water depths for the offshore waters of South Australia, with depth values representing depths to the seabed. Data were collected as part of the National Mapping Bathymetric Program, which was designed to provide generalised detail of the seabed of the Continental Shelf. Depth values were delineated into 6 categories; 0 to $10 \mathrm{~m}, 10$ to $20 \mathrm{~m} ; 20$ to $30 \mathrm{~m} ; 30$ to $40 \mathrm{~m}_{;} 40$ to 50 $\mathrm{m}$ and $50+\mathrm{m}$. We required representation of each depth category occurring within each of the 8 bioregions. This provided an additional 45 conservation features.

\section{Protected areas}

This data layer provides an accurate location for the legal boundaries of both terrestrial and marine reserves and was used to formulate marine reserve design scenarios. We generated a user-defined marine reserve theme as a subset of protected areas derived from the Australian Collaborative Protected Area Database. It includes areas recognised as marine reserves, as well as coastal/offshore island reserves with significant marine components. In this paper, rock lobster sanctuaries and most netting closures were not included. Consequently, South Australia's existing marine reserves comprised 17 marine reserves with a total area of approximately $2600 \mathrm{~km}^{2}$. The location of individual reserves is shown in Fig. 2, with reserves identified below.

$\begin{array}{ll}\text { (1) } & \text { Great Australian Bight Marine Park } \\ (2) & \text { Point Labatt } \\ (3) & \text { Neptune Islands } \\ (4) & \text { Sir Joseph Banks Group } \\ (5) & \text { Whyalla-Cowleds Landing } \\ (6) & \text { Blanche Harbour-Douglas Bank }\end{array}$

$\begin{array}{ll}(7) & \text { Yatala Harbour } \\ (8) & \text { Goose Island } \\ (9) & \text { Troubridge Hill } \\ (10) & \text { Zanoni } \\ (11) & \text { Barker Inlet/Chapman Creek } \\ (12) & \text { Port Noarlunga/Aldinga Reef }\end{array}$

$\begin{array}{ll}\text { (13) } & \text { West Island } \\ \text { (14) } & \text { The Pages } \\ \text { (15) } & \text { American River } \\ \text { (16) } & \text { Seal Bay/Bales Beach } \\ \text { (17) } & \text { Coorong }\end{array}$


to support inquiry about what level of uncertainty is acceptable. They do this by being flexible, by providing $>1$ solution and responding well to complex decision rules. We believe that mathematical algorithms provide a means to (1) consider different levels of representation, replication and spatial constraints; (2) integrate multiple goals within a single planning framework; and (3) inform where reservation should proceed.

Acknowledgements. The authors would like to thank the South Australian government and K. S. Edyvane for approval to access data used in this study. The first author is grateful to The Ecology Centre for financial support and to A. J. Tyre, I. R. Ball and W. Rochester for helpful discussions during the course of this research. Finally, we would like to thank 4 anonymous referees for their useful comments on earlier drafts of this manuscript.

\section{LITERATURE CITED}

Agardi T (2000) Information needs for marine protected areas: scientific and societal. Bull Mar Sci 66(3):875-888

Allison GW, Lubchenco J, Carr MH (1998) Marine Reserves are necessary but not sufficient for marine conservation. Ecol Appl Suppl 8:S79-S92

Allison GW, Gaines SD, Lubchenco J, Possingham HP (2003) Ensuring persistence of marine reserves: catastrophes require adopting an insurance factor. Ecol Appl Suppl 13(1):S8-S24

ANZECC (1999) Strategic plan of action for the National Representative System of Marine Protected Areas: a guide for action by Australian governments. Australian and New Zealand Environment and Conservation Council, Task Force on Marine Protected Areas. Environment Australia, Canberra

Ardron J, Lash J, Haggarty D (2001) Designing a network of MPAs in the central coast of British Columbia, Vol 1. Overview. Living Oceans Society, Sointula, BC

Ball IR (2000) Mathematical applications for conservation ecology: the dynamics of tree hollows and the design of nature reserves. PhD thesis, University of Adelaide

Ball IR, Possingham HP (2001) The design of marine protected areas: adapting terrestrial techniques. In: Ghassemi $\mathrm{F}$, Whetton P, Little R, Littleboy M (eds) Integration models for natual resources, management across disciplines, issues and scales: Proc Int Congr on Modelling and Simulation (MODSIM), Vol 2. The Australian National University, Canberra, p 769-774

Ballantine W (1997) Design principles for systems of 'no-take' marine reserves. Workshop on the design and monitoring of marine reserves. Feb 18-20, Fisheries Centre, University of British Columbia, Vancouver

Beck MW, Odaya M (2001) Ecoregional planning in marine environments: identifying priority sites for conservation in the northern Gulf of Mexico. Aquat Conserv 11(4): 235-242

Bedward M, Pressey RL, Nicholls AO (1991) Scores and score classes for evaluation criteria - a comparison based on the cost of reserving all natural features. Biol Conserv 56(3): 281-294

Boersma PD, Parrish JK (1999) Limiting abuse: marine protected areas, a limited solution. Ecol Econ 31(2):287-304
Carleton Ray G (1999) Coastal-marine protected areas: agonies of choice. Aquat Conserv 9:607-614

Cocks KD, Baird IA (1989) Using mathematical programming to address the multiple reserve selection problem: an example from the Eyre Peninsula, South Australia. Biol Conserv 49:113-130

Costanza R, Andrade F, Antunes $\mathrm{P}$, van den Belt $\mathrm{M}$ and 6 others (1999) Ecological economics and sustainable governance of the oceans. Ecol Econ 31(2):171-187

Creswell ID, Thomas GM (1997) Terrestrial and marine protected areas in Australia (1997). Environment Australia, Biodiversity Group, Canberra

Crowder LB, Lyman SJ, Figueira WF, Priddy J (2000) Sourcesink population dynamics and the problem of siting marine reserves. Bull Mar Sci 66(3):799-820

Edyvane KS (1999a) Conserving marine biodiversity in South Australia. Part 1. Background, status, review and framework for marine biodiversity conservation in South Australia: final report for Biodiversity Group (Environment Australia). SARDI Research Report No 38. South Australian Research and Development Institute, Department of Primary Industries, Adelaide

Edyvane KS (1999b) Conserving marine biodiversity in South Australia. Part 2. Identification of areas of high conservation value in South Australia: final report for Biodiversity Group (Environment Australia), SARDI Research Report No 39. South Australian Research and Development Institute, Department of Primary Industries, Adelaide

Ferrier S, Pressey RL, Barrett TW (2000) A new predictor of the irreplaceability of areas for achieving a conservation goal, its application to real-world planning, and a research agenda for further refinement. Biol Conserv 93:303-325

Flather CH, Wilson KR, Dean DJ, McComb WC (1997) Identifying gaps in conservation networks of indicators and uncertainty in geographic-based analyses. Ecol Appl 7(2): $531-542$

Freitag S, Nicholls AO, van Jaarsveld AS (1998) Dealing with established reserve networks and incomplete distribution data sets in conservation planning. S Afr J Sci 94(2): $79-86$

Government of South Australia (1998) Our seas and coasts: a marine and estuarine strategy for South Australia. The Marine and Estuarine Steering Committee for the South Australian Government, Adelaide

Government of South Australia (2001) Marine protected areas: a shared vision. Draft for public consultation. Government of South Australia, Adelaide

Hockey PAR, Branch GM (1997) Criteria, objectives and methodology for evaluating marine protected areas in South Africa. S Afr J Mar Sci 18:369-383

IMCRA Technical Group (1997) Interim Marine and Coastal Regionalisation for Australia: an ecosystem-based classification for marine and coastal environments - version 3.2. Environment Australia, Commonwealth Department of the Environment, Canberra

Kelleher G (1997) A global representative system of marine protected areas. Ocean Coast Manag 32(2):123-126

Kelleher G, Kenchington R (1992) Guidelines for establishing marine protected areas. In: A marine conservation and development report. IUCN, Gland, Switzerland, p 79

Kirkpatrick JB (1983) An iterative method for establishing priorities for selection of nature reserves: an example from Tasmania. Biol Conserv 25:127-134

Lauck T, Clark CW, Mangal M, Munro GR (1998) Implementing the precautionary principle in fisheries management through marine reserves. Ecol Appl Suppl 8(1):S72-S78

Leslie H, Ruckelshaus M, Ball IR, Andelman S, Possingham 
HP (2003) Using siting algorithms in the design of marine reserve networks. Ecol Appl Suppl 13(1):S185-S198

Margules CR, Nicholls AO (1988) Selecting networks of reserves to maximise biological diversity. Biol Conserv 43: 63-76

Margules CR, Pressey RL (2000) Systematic conservation planning. Nature 405:243-253

McDonnell M, Possingham HP, Ball IR, Cousins E (2002) Mathematical methods for spatially cohesive reserve design. Environ Model Assess 7(2):107-114

Nicholls AO, Margules CR (1993) An upgraded reserve selection algorithm. Biol Conserv 64:165-169

Noss RF (1990) Indicators for monitoring biodiversity: a hierarchical approach. Conserv Biol 4(6):355-364

Possingham HP, Ball I, Andelman S (2000) Mathematical methods for identifying representative reserve networks. In: Ferson S, Burgman M (eds) Quantitative methods for conservation biology. Springer-Verlag, New York, p 291-306

Possingham HP, Andelman SJ, Noon BR, Trombulak S, Pulliam HR (2001) Making smart conservation decisions. In: Soule ME, Orians GH (eds) Research priorities for nature conservation. Island Press, Washington, DC, p 225-244

Pressey RL, Cowling RM (2001) Reserve selection algorithms and the real world. Conserv Biol 15(1):275-277

Pressey RL, Nicholls AO (1989) Efficiency in conservation evaluation: scoring versus iterative approaches. Biol Conserv 50:199-218

Pressey RL, Tully SL (1994) The cost of ad hoc reservation-a case-study in western New South Wales. Aust J Ecol 19(4): 375-384

Pressey RL, Humphries CJ, Margules CR, Vane-Wright RI, Williams PH (1993) Beyond opportunism-key principles for systematic reserve selection. Trends Ecol Evol 8(4): $124-128$

Pressey RL, Johnson IR, Wilson PD (1994) Shades of irreplaceability - towards a measure of the contribution of sites to a reservation goal. Biodivers Conserv 3(3):242-262

Pressey RL, Ferrier S, Hutchinson CD, Sivertsen DP, Manion G (1995) Planning for negotiation: using an interactive geographic information system to explore alternative protected area networks. In: Saunders DA, Craig JL, Mattiske

Editorial responsibility: Otto Kinne (Editor),

Oldendorf/Luhe, Germany
EM (eds) Nature conservation 4: the role of networks. Surrey Beatty \& Sons, Sydney, p 23-33

Pressey RL, Possingham HP, Day JR (1997) Effectiveness of alternative heuristic algorithms for identifying indicative minimum requirements for conservation reserves. Biol Conserv 80(2):207-219

Pulliam HR, Danielson BJ (1991) Sources, sinks, and habitat selection: a landscape perspective on population dynamics. Am Nat 137(Suppl):50-66

Regan HM, Colyvan M, Burgman MA (2000) A proposal for fuzzy International Union for the Conservation of Nature (IUCN) categories and criteria. Biol Conserv 92:101-108

Roberts CM (1998) Sources, sinks and the design of marine reserve networks. Fisheries 23(7):16-19

Roberts CM, Andelman S, Branch G, Bustamante RH and 10 others (2003) Ecological criteria for evaluating candidate sites for marine reserves. Ecol Appl Suppl 13(1): S199-S214

Rodrigues ASL, Tratt R, Wheeler BD, Gaston KJ (1999) The performance of existing networks of conservation areas in representing biodiversity. Proc R Soc Lond B Biol Sci 266: 1453-1460

Stewart RR, Possingham HP (in press) A framework for systematic marine reserve design in South Australia: a case study. In: Proc Inaugural World Congr on Aquatic Protected Areas, 14-17 Aug 2002, Cairns

Vanderklift MA, Ward TJ, Phillips JC (1998) Use of assemblages derived from different taxonomic levels to select areas for conserving marine biodiversity. Biol Conserv 86: $307-315$

Vane-Wright RI, Humphries CJ, Williams PH (1991) What to protect-systematics and the agony of choice. Biol Conserv 55(3):235-254

Ward TJ, Vanderklift MA, Nicholls AO, Kenchington RA (1999) Selecting marine reserves using habitats and species assemblages as surrogates for biological diversity. Ecol Appl 9(2):691-698

Williams P, Gibbons D, Margules CR, Rebelo A, Humphries C, Pressey RL (1996) A comparison of richness hotspots, rarity hotspots, and complementary areas for conserving diversity of British birds. Conserv Biol 10(1):155-174

Submitted: May 31, 2002; Accepted: January 7, 2003

Proofs received from author(s): April 8, 2003 